Check for updates

Cite this: RSC Adv., 2021, 11, 23948

\title{
Copper sulfide as the cation exchange template for synthesis of bimetallic catalysts for $\mathrm{CO}_{2}$ electroreduction $\uparrow$
}

\author{
Jinghan Li, (D) abc Junrui Li, (iD) ${ }^{\text {bc }}$ Chaochao Dun, (D) ${ }^{d}$ Wenshu Chen, (D) ${ }^{\mathrm{e}}$ Di Zhang, ${ }^{a}$ \\ Jiajun Gu, (iD) a Jeffrey J. Urban (iD) and Joel W. Ager (iD *bc
}

\begin{abstract}
Among metals used for $\mathrm{CO}_{2}$ electroreduction in water, $\mathrm{Cu}$ appears to be unique in its ability to produce $\mathrm{C} 2+$ products like ethylene. Bimetallic combinations of $\mathrm{Cu}$ with other metals have been investigated with the goal of steering selectivity via creating a tandem pathway through the $\mathrm{CO}$ intermediate or by changing the surface electronic structure. Here, we demonstrate a facile cation exchange method to synthesize $\mathrm{Ag} / \mathrm{Cu}$ electrocatalysts for $\mathrm{CO}_{2}$ reduction using $\mathrm{Cu}$ sulfides as a growth template. Beginning with $\mathrm{Cu}_{2-x} \mathrm{~S}$ nanosheets (C-nano-0, $100 \mathrm{~nm}$ lateral dimension, $14 \mathrm{~nm}$ thick), varying the $\mathrm{Ag}^{+}$concentration in the exchange solution produces a gradual change in crystal structure from $\mathrm{Cu}_{7} \mathrm{~S}_{4}$ to $\mathrm{Ag}_{2} \mathrm{~S}$, as the $\mathrm{Ag} / \mathrm{Cu}$ mass ratio varies from 0.3 to 25 (CA-nano- $x, x$ indicating increasing Ag fraction). After cation exchange, the nanosheet morphology remains but with increased shape distortion as the $\mathrm{Ag}$ fraction is increased. Interestingly, the control (C-nano-0) and cation exchanged nanosheets have very high faradaic efficiency for producing formate at low overpotential ( $-0.2 \mathrm{~V}$ vs. RHE). The primary effect of $\mathrm{Ag}$ incorporation is increased production of $\mathrm{C} 2+$ products at $-1.0 \mathrm{~V}$ vs. RHE compared with C-nano-0, which primarily produces formate. Cation exchange can also be used to modify the surface of Cu foils. A two-step electro-oxidation/sulfurization process was used to form $\mathrm{Cu}$ sulfides on $\mathrm{Cu}$ foil (C-foil- $x$ ) to a depth of a few $10 \mathrm{~s}$ of microns. With lower $\mathrm{Ag}^{+}$concentrations, cation exchange produces uniformly dispersed Ag; however, at higher concentrations, Ag particles nucleate on the surface. During $\mathrm{CO}_{2}$ electroreduction testing, the product distribution for $\mathrm{Ag} / \mathrm{Cu}$ sulfides on $\mathrm{Cu}$ foil (CA-foil- $x-y$ ) changes in time with an initial increase in ethylene and methane production followed by a decrease as more $\mathrm{H}_{2}$ is produced. The catalysts undergo a morphology evolution towards a nest-like structure which could be responsible for the change in selectivity. For cation-exchanged nanosheets (CA-nano- $x$ ), pre-reduction at negative potentials increases the $\mathrm{CO}_{2}$ reduction selectivity compared to tests of as-synthesized material, although this led to the aggregation of nanosheets into filaments. Both types of bimetallic catalysts are capable of selective reduction of $\mathrm{CO}_{2}$ to multi-carbon products, although the optimal configurations appear to be metastable.
\end{abstract}

Received 16th May 2021

Accepted 21st June 2021

DOI: $10.1039 / \mathrm{d} 1 \mathrm{ra03811 \textrm {g }}$

rsc.li/rsc-advances

\section{Introduction}

$\mathrm{CO}_{2}$ electroreduction $\left(\mathrm{CO}_{2} \mathrm{R}\right)$ has become one of the most promising strategies towards achieving a carbon-neutral environment. Provided that it is powered by a renewable energy source, it can sustainably convert the greenhouse gas $\mathrm{CO}_{2}$ into fuels like methanol and ethanol, and commodity chemicals such as ethylene. ${ }^{1,2} \mathrm{Cu}$ has been of intense interest as an electrocatalyst for this reaction, as it is selective for $\mathrm{CO}_{2}$ reduction over water reduction and can produce $\mathrm{C} 2+$ products, due to its positive adsorption energy for $\mathrm{H}^{*}$ and more optimal binding energy for $\mathrm{CO}_{2}$ and related intermediates, compared to other metals. ${ }^{3-6}$ Still, it has been difficult to control selectivity to a single $\mathrm{CO}_{2}$ reduction product. To this end, many research groups investigated alloys and bimetallic configurations of $\mathrm{Cu}$ with other metals to attempt to tune the overall catalyst performance. ${ }^{3}$ 
There are two main conceptual strategies for $\mathrm{Cu}$-based alloy and bimetallic electrocatalysts. One approach is to create a tandem catalyst mechanism via combining $\mathrm{Cu}$ with other $\mathrm{CO}-$ producing elements like $\mathrm{Ag}$ or $\mathrm{Au}$. In this concept, the crucial intermediate CO made on the second metal surface can transfer to $\mathrm{Cu}$ to be further reduced..$^{7-12}$ For example, polycrystalline copper foil with $\mathrm{Au}$ nanoparticles favors the generation of oxygenates over hydrocarbons at low overpotentials. ${ }^{13}$ Increased $\mathrm{CO}$ concentration achieved by $\mathrm{Ag}$ nanoparticles on oxidederived $\mathrm{Cu}$ nanowires may also open another pathway, namely ${ }^{*} \mathrm{CO}+{ }^{*} \mathrm{CH}_{x}$ coupling towards increased ethanol generation. ${ }^{14}$ A second approach is to change the local electronic structure of $\mathrm{Cu}$ by alloying with the other elements in order to tune the binding strength towards intermediates. ${ }^{15-19}$ For example, $\mathrm{Ag}$ atoms in the bimetallic $\mathrm{Cu}-\mathrm{Ag}$ catalyst create a diversity of binding configurations compared with pure $\mathrm{Cu}$ that facilitates the production of ethanol. ${ }^{20}$ The compressive surface strain induced by $\mathrm{Ag}$ reduces the $\mathrm{H}^{*}$ adsorbates, leading to the selective suppression of HER and favors the production of multi-carbon oxygenates. ${ }^{21} \mathrm{Ag}_{2} \mathrm{Cu}_{2} \mathrm{O}_{3}$, with a 1:1 stoichiometric ratio between $\mathrm{Ag}$ and $\mathrm{Cu}$, can be used to produce bimetallic catalysts with a known composition and uniform distribution on the atomic scale. When applied to CO reduction, catalysts of this type can achieve $92 \%$ faradaic efficiency towards $\mathrm{C} 2+$ products at $600 \mathrm{~mA} \mathrm{~cm}{ }^{-2} .^{22}$

In this context, a facile strategy to introduce another element of specific concentration mixed with $\mathrm{Cu}$ on a variety of catalyst morphologies would be beneficial. This motivated us to investigate the cation exchange method, whereby a guest metal is introduced in the ion-form to replace the host metal ion in the compounds partially or entirely. This chemical conversion method has been widely employed to metal sulfides and oxides to achieve metastable facets, heteroatom doping, and introducing defect and strain, and also can be used to make multimetal catalysts. ${ }^{23}$ Specific to $\mathrm{CO}_{2}$ reduction, the choice of the parent compound used for cation exchange may influence catalyst performance. We note here the reported enhancement in $\mathrm{C} 2+$ product selectivity for oxide-derived copper as compared to metallic copper, some of which has been attributed to increased roughness and grain boundaries which form as a result of in situ reduction of the oxide starting material. ${ }^{24-27}$ Bearing this in mind, we hypothesized that $\mathrm{Cu}$ sulfide could serve as a convenient cation exchange template for the formation of bimetallic $\mathrm{CO}_{2} \mathrm{R}$ electrocatalysts. We further hypothesized that the depletion of sulfur which occurs at the negative potential used to drive $\mathrm{CO}_{2} \mathrm{R}$ could lead to morphology changes which could be beneficial for control of selectivity. ${ }^{11,28}$

To test these hypotheses, we developed a cation exchange method to accommodate two common catalyst designs for $\mathrm{CO}_{2}$ reduction: nanoparticles and foil electrodes. Ag was selected as the second metal as it is selective for the production of $\mathrm{CO}$, which is believed to be the key intermediate for the formation of $\mathrm{C} 2+$ products. For creating nanoscale catalysts, we prepared $\mathrm{Cu}$ sulfide nanosheets (C-nano-0) by colloidal synthesis, while for modifying $\mathrm{Cu}$ surfaces, $\mathrm{Cu}$ sulfides were directly grown on $\mathrm{Cu}$ foil using electro-oxidation followed by sulfurization. In both cases, the $\mathrm{Ag} / \mathrm{Cu}$ mass ratio of the catalysts could be controlled at the cation exchange step. For nanosheets, the $\mathrm{Ag} / \mathrm{Cu}$ mass ratio can reach 25 with the original structure remaining nearly intact. Cation exchange on surface-modified $\mathrm{Cu}$ foils (C-foil- $x$ ) produces well-dispersed $\mathrm{Ag}$ at low concentrations but leads to Ag particle nucleation at higher concentrations. Compared with C-nano-0 controls, $\mathrm{CO}_{2}$ reduction on moderately cation exchanged $\mathrm{Ag} / \mathrm{Cu}$ sulfide nanosheets (CA-nano-2) increases the selectivity to $\mathrm{C} 2+$ products at $-1.0 \mathrm{~V} v s$. RHE. The selectivity for $\mathrm{CO}_{2}$ reduction of cation exchanged foils increases and then decreases over a period of 16 hours. Both the nanosheets and copper foil catalysts undergo noticeable morphology changes during the $\mathrm{CO}_{2}$ reduction, which may explain why the product distributions change as the $\mathrm{CO}_{2}$ reduction proceeds.

\section{Synthesis procedures}

The synthesis methods are summarized here; full details are in ESI. $\dagger$

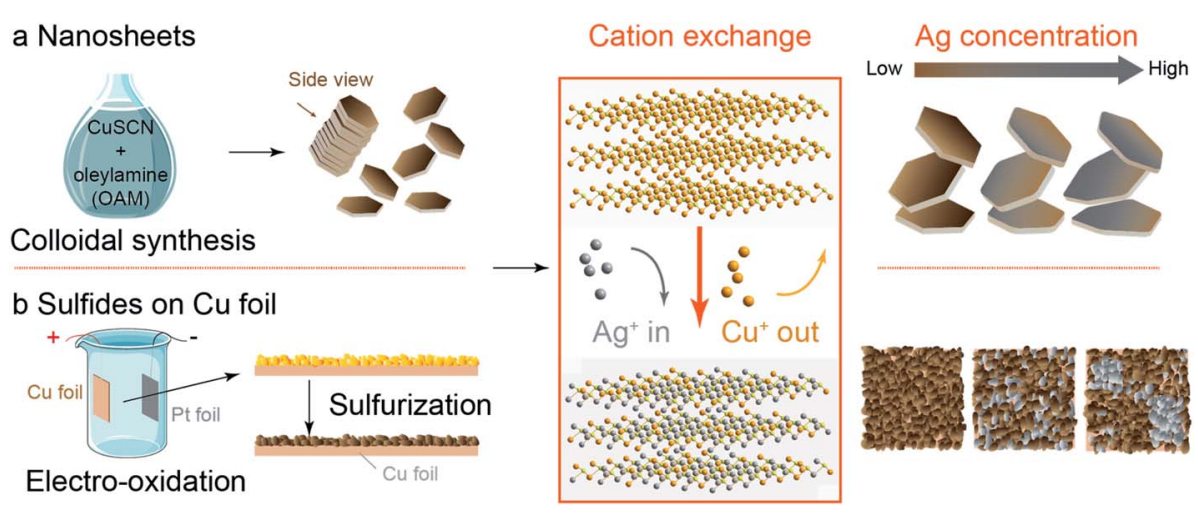

Scheme 1 Synthetic strategies for Ag/Cu sulfide catalysts. (a) Cu sulfide nanosheets (C-nano-0, $100 \mathrm{~nm}$ lateral dimension, $14 \mathrm{~nm}$ thick) were obtained through colloidal synthesis with CuSCN in oleylamine (OAM). (b) Cu sulfides on Cu foil (C-foil-x) were obtained through electrooxidation in $1 \mathrm{M} \mathrm{NaOH}$ to produce an oxide layer of a few $10 \mathrm{~s}$ of microns thick followed by sulfurization with $0.1 \mathrm{M} \mathrm{Na} 2 \mathrm{~S}$. After cation exchange where $\mathrm{Ag}^{+}$replaces the $\mathrm{Cu}^{+}$in the $\mathrm{Cu}$ sulfides, $\mathrm{Ag} / \mathrm{Cu}$ sulfide nanosheets (CA-nano- $x$ ) remain nanosheet structure with some distortion in shape as the $\mathrm{Ag} / \mathrm{Cu}$ mass ratio ranges from 0.3 to 25; while for $\mathrm{C}$-foil- $x, \mathrm{Ag}$ nucleates at higher $\mathrm{Ag}$ concentration, that impedes the uniform distribution of $\mathrm{Ag}$ and $\mathrm{Cu}$. 
Table 1 Cation-exchanged nanosheet samples with precursor and reagent contents and mass ratios as measured by inductively coupled plasma mass spectroscopy (ICP-MS)

\begin{tabular}{llll}
\hline Label & C-nano-0 $(\mathrm{mg})$ & $\mathrm{AgNO}_{3}(\mathrm{mg})$ & $\mathrm{Ag} / \mathrm{Cu}$ mass ratio \\
\hline C-nano-0 & - & 0 & - \\
CA-nano-1 & 30 & 15 & 0.3 \\
CA-nano-2 & 30 & 30 & 0.8 \\
CA-nano-3 & 30 & 45 & 2.3 \\
CA-nano-4 & 30 & 90 & 25
\end{tabular}

\section{Cu sulfide nanosheets (C-nano-0)}

C-nano-0 was synthesized with a modified colloidal synthesis recipe (Scheme 1a, see also Table 1 for sample nomenclature). ${ }^{29,30}$ Typically, $257 \mathrm{mg}$ copper(I) thiocyanate (CuSCN) was dispersed in $25 \mathrm{~mL}$ oleylamine (OAM). The mixture was first degassed and heated in $\mathrm{N}_{2}$ to $240{ }^{\circ} \mathrm{C}$ for $30 \mathrm{~min}$. The synthesized nanosheets were then washed with hexanes and ethanol to remove the surface ligands and dispersed in hexanes for storage.

\section{Cu sulfides on $\mathrm{Cu}$ foil (C-foil- $x$ )}

$\mathrm{Cu}$ sulfides on $\mathrm{Cu}$ foil (C-foil- $x$, see Table 2 for sample nomenclature) were synthesized with a two-step electro-oxidation/ sulfurization process (Scheme 1b). Cu foil was first cleaned and etched by $4 \mathrm{M} \mathrm{HCl}$. After that, $\mathrm{Cu}(\mathrm{OH})_{2}$ was grown on the $\mathrm{Cu}$ foil by electro-oxidation in $1 \mathrm{M} \mathrm{NaOH}$. The electrode was then immersed in $0.1 \mathrm{M} \mathrm{Na}_{2} \mathrm{~S}$ at $90{ }^{\circ} \mathrm{C}$ for $12 \mathrm{~h}$ to obtain $\mathrm{Cu}$ sulfides. ${ }^{31}$ The current density set during the electro-oxidation process affects the grain size, as will be discussed later. Carbon substrates including carbon paper and carbon cloth with deposited $\mathrm{Cu}$ as the $\mathrm{Cu}$ source and chemical oxidation for the growth of $\mathrm{Cu}(\mathrm{OH})_{2}$ were also tried but were less successful; see ESI for details (Fig. S1-S6†).

\section{Cation exchange method}

For nanosheet samples, the hexanes dispersion containing Cnano-0 was added to an OAM solution $(7 \mathrm{~mL})$ containing the $\mathrm{Ag}$ precursor $\mathrm{AgNO}_{3} .{ }^{29}$ The solution was first degassed and heated to $50{ }^{\circ} \mathrm{C}$ in $\mathrm{N}_{2}$ and kept for another $30 \mathrm{~min}$ to complete

Table 2 Sulfides on $\mathrm{Cu}$ foil with electro-oxidation and cation exchange parameters

\begin{tabular}{lll}
\hline Label & Current density $\left(\mathrm{mA} \mathrm{cm}^{-2}\right)$ & $\mathrm{AgNO}_{3}(\mathrm{mg})$ \\
\hline C-foil-10 & 10 & - \\
C-foil-20 & 20 & - \\
C-foil-30 & 30 & - \\
C-foil-40 & 40 & - \\
CA-foil-20-10 & 20 & 10 \\
CA-foil-20-20 & 20 & 20 \\
CA-foil-20-30 & 20 & 30 \\
CA-foil-20-40 & 20 & 40 \\
CA-foil-40-40 & 40 & 40
\end{tabular}

the cation exchange reaction. The nanosheets were then washed with ethanol and hexanes and dispersed in hexanes for storage. The samples are denoted CA-nano- $x$ as shown in Table 1.

To perform cation exchange for the $\mathrm{Cu}$ sulfides on $\mathrm{Cu}$ foil $(\mathrm{C}$ foil- $x$ ), $\mathrm{AgNO}_{3}$ was added to OAM with $\mathrm{N}_{2}$ bubbled to the solution in small Petri-dish. After the solution was heated to $50{ }^{\circ} \mathrm{C}$ and well mixed, C-foil- $x$ was placed in the solution and kept for another $30 \mathrm{~min}$. The electrode was then cleaned with ethanol and hexanes and dried with $\mathrm{N}_{2}$ flow. The $\mathrm{Ag} / \mathrm{Cu}$ sulfides on $\mathrm{Cu}$ foil were named CA-foil- $x-y$ with $x$ denoting the current density and $y$ the relative $\mathrm{Ag}$ fraction (Table 2). As discussed later, the concentration of $\mathrm{Ag}^{+}$in the cation exchange solution affected the dispersion of $\mathrm{Ag}$, with uniform distributions being formed at low concentrations and $\mathrm{Ag}$ particles nucleating on the surface at high concentrations.

\section{Electrochemical characterization and product analysis}

\section{Electrode preparation and $\mathrm{CO}_{2}$ reduction}

For nanosheet samples (C-nano-0 and CA-nano- $x$ ), the catalysts were first anchored on carbon black at a $1: 1$ mass ratio of catalyst to carbon. The catalyst was dispersed in ethanol and water, and Nafion was added as the binder. After sonication, the homogeneous catalyst ink was drop cast on glassy carbon substrates (GC) followed by drying overnight at room temperature. Typically, the catalysts were tested with the loading of $0.6 \mathrm{mg}$ on an electrode area of $0.785 \mathrm{~cm}^{2}$. Sulfides on $\mathrm{Cu}$ foil (C-foil- $x$ and CA-foil- $x-y$ ) were tested directly without further modification. The $\mathrm{CO}_{2}$ reduction was conducted in a three-electrode system with $0.05 \mathrm{M} \mathrm{K}_{2} \mathrm{CO}_{3}$ as the electrolyte and $\mathrm{Pt}$ and $\mathrm{Ag} / \mathrm{AgCl}$ (saturated $\mathrm{KCl}$ ) as the reference and counter electrode, respectively. The cathodic and anodic chambers were separated by an anion exchange membrane. $\mathrm{CO}_{2}$ was purged at $5 \mathrm{sccm}$ to the cathodic chamber, and the test started after 15 min $\mathrm{CO}_{2}$ purging to ensure complete saturation, after which the electrolyte becomes $0.1 \mathrm{M}$ bicarbonate. We note that the freshly prepared electrodes are not active for $\mathrm{CO}_{2} \mathrm{R}$ and initially favour $\mathrm{H}_{2}$ production. The time evolution of the catalysts and the induced changes in the product profiles under $\mathrm{CO}_{2}$ electroreduction conditions are thus discussed in detail below.

\section{Product detection}

The gas products, including $\mathrm{H}_{2}$, CO, methane, ethylene, and ethane, were detected by online gas chromatography (GC) using methods reported previously. ${ }^{32,33}$ Typically, GC sampling was started $5 \mathrm{~min}$ after the test began, and the results were given by the average of the second to the last sample. The electrolyte was collected after each test and analysed by nuclear magnetic resonance (NMR) for liquid products, including formate, methanol, ethanol, n-propanol, and other low-concentration C2+ products such as acetate, glycolaldehyde, allyl alcohol, acetaldehyde, acetone, and propionaldehyde. ${ }^{6}$ 


\section{Results and discussion}

\section{Cu sulfide nanosheets (C-nano-0)}

TEM images of C-nano-0 made by colloidal synthesis are presented in Fig. 1. The nanosheets have a hexagonal shape with a lateral size of $100 \mathrm{~nm}$ and a thickness of $14 \mathrm{~nm}$, as shown in Fig. 1a-c. As shown in the HRTEM image (Fig. 1d), the planes with the spacing of $1.95 \AA$ and a $60^{\circ}$ angle in between can be assigned to the ( $\left.\begin{array}{lll}0 & 16 & 0\end{array}\right)$ and ( $\left.\begin{array}{lll}0 & 8 & 6\end{array}\right)$ planes of monoclinic $\mathrm{Cu}_{7} \mathrm{~S}_{4}{ }^{34}$ In addition, the $3.28 \AA$ lattice spacing in the side view HRTEM image matches the (16 00 ) plane (Fig. 1e). Some areas exhibit less contrast with no clear lattice; these areas may have a high defect concentration or be amorphous. The nanosheets have a large specific surface area which could be beneficial for catalytic activity.

XPS spectra of C-nano-0 provide information about the surface condition of the nanosheets (Fig. S7 and S8 $\dagger$ ). The $\mathrm{S} / \mathrm{Cu}$ atomic ratio was 0.67 , slightly higher than the stoichiometric ratio of $\mathrm{Cu}_{7} \mathrm{~S}_{4}$, supporting the $\mathrm{Cu}_{7} \mathrm{~S}_{4}$ lattice structure with a sulfur-rich surface of C-nano-0. Most $\mathrm{Cu}$ in the nanosheets has the valence state of $1+$, the deviation of the spectrum may result from the defects in the nanosheets and $\mathrm{Cu}^{2+} \cdot{ }^{35,36}$ The existence of $\mathrm{N}$, the peaks at $163 \mathrm{eV}$ in the $\mathrm{S}_{2 \mathrm{p}}$ spectrum, and the peak at $286 \mathrm{eV}$ in the $\mathrm{C}_{1 \mathrm{~s}}$ spectrum indicate the presence of a small amount of residual ligand $-\mathrm{SCN}$ from the precursor CuSCN. ${ }^{37}$ It is also possible that OAM is present despite the washing steps designs to remove it; however, prior studies have shown that it does not block active sites for $\mathrm{CO}_{2}$ electroreduction. ${ }^{38}$

\section{Bimetallic sulfide nanosheets (CA-nano- $x$ )}

The mass ratio of $\mathrm{Ag} / \mathrm{Cu}$ concentration was well controlled from 0.3 (CA-nano-1) to 25 (CA-nano-4) (Table S1 $\dagger$ ). The ratio of Ag and $\mathrm{Cu}$ in samples were quantified by inductively coupled plasma mass spectroscopy (7900 ICP-MS, Agilent, ICP) using the He mode. The internal standard was Ge or Rh selected based on its first ionization potential and $M / Z$ as compared to $\mathrm{Cu}$ or $\mathrm{Ag}$, respectively. As shown in the XRD spectra (Fig. 2a), the crystal structure of the nanosheets undergoes a noticeable change as the $\mathrm{Ag}$ concentration increases. Prior to cation exchange, the nanosheets have the crystal structure of $\mathrm{Cu}_{7} \mathrm{~S}_{4}$ (PDF \#23-0958), ${ }^{39}$ in agreement with TEM. For a small amount of cation exchange (CA-nano-1), the crystal structure remains the same as the Cnano-0 with the most prominent peak in the XRD pattern at $\sim 48^{\circ}$ being assigned to $\mathrm{Cu}_{7} \mathrm{~S}_{4}\left(\begin{array}{lll}0 & 16 & 0\end{array}\right)$. At higher Ag concentrations, a shift of the peak near $\sim 32^{\circ}$ is observed from the yellow marked position for $\mathrm{Cu}_{7} \mathrm{~S}_{4}$ to the purple marked $\mathrm{Ag}_{2} \mathrm{~S}$ position. The appearance (CA-nano-2) and shift of the peak pointed by the arrow as $\mathrm{Ag}$ concentration increases support the gradual structural change. With the ratio of $\mathrm{Ag} / \mathrm{Cu}$ reaches 25 (CA-nano4 ), the structure completely changes to $\mathrm{Ag}_{2} \mathrm{~S}$, demonstrated by the peak at $\sim 34^{\circ}$, which can be assigned to (1 121 ) planes. The morphology also undergoes obvious change with large shape distortion and the nanosheet structure remains (Fig. 2b), while with $\mathrm{Ag} / \mathrm{Cu}$ ratio less than 1 , the hexagonal shape remains with only minor changes in shape or thickness (Fig. S9-S12 $\dagger$ ).

Fig. 2c-g show the morphology, elemental distribution, and typical lattice structure of CA-nano-2 $(\mathrm{Ag} / \mathrm{Cu}=0.8)$ as determined by SEM and TEM. The morphology uniformity of the nanosheets decreases compared with that before cation exchange but the enlarged SEM image with elemental mapping still provides evidence of the uniform distribution of $\mathrm{Ag}, \mathrm{Cu}$, and S, without any spatial separation (Fig. 2d).

HRTEM images obtained from the side-view demonstrate the existence of crystalline $\mathrm{Ag}_{2} \mathrm{~S}$. In Fig. 2e, observed from

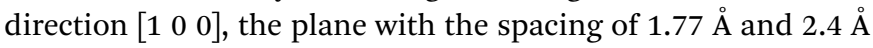
can be assigned to the planes ( $\left.\begin{array}{lll}0 & 4 & 0\end{array}\right)$ and ( $\left.\begin{array}{lll}0 & 1 & 3\end{array}\right)$, respectively. Besides, it shows a composition of small crystals with different
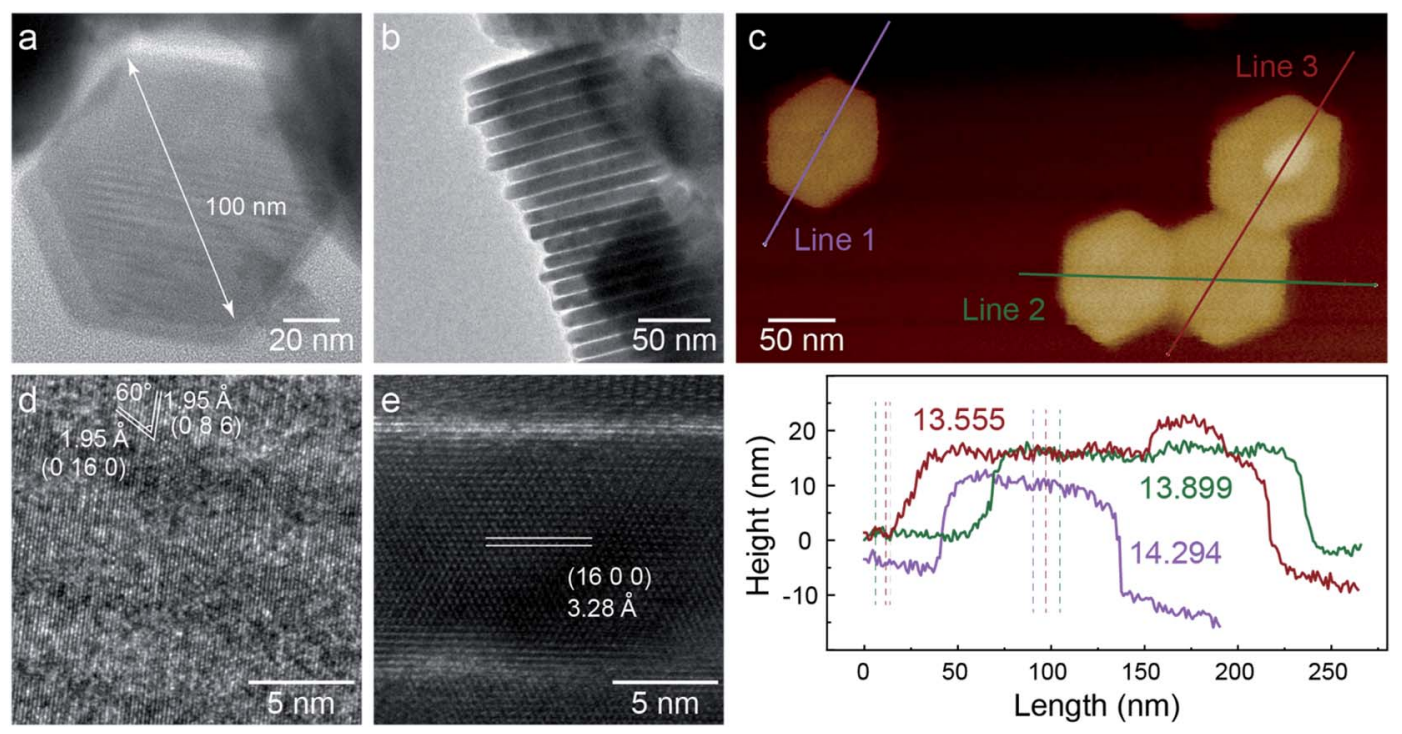

Fig. 1 TEM characterization of C-nano-0. (a) C-nano-0 has a hexagonal shape with a lateral size of $100 \mathrm{~nm}$. (b) Side-view of a stack of nanosheets. (c) AFM image and height information, showing the thickness of $14 \mathrm{~nm}$. ( $\mathrm{d}$ and e) High-resolution TEM (HRTEM) image shows the lattice structure of monoclinic $\mathrm{Cu}_{7} \mathrm{~S}_{4}$. 

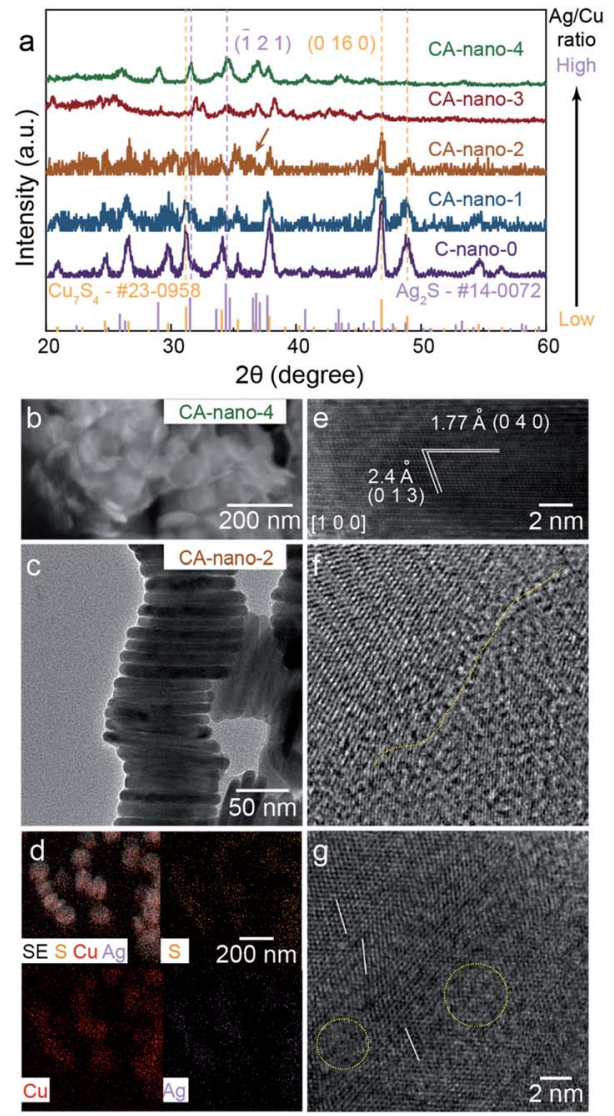

Fig. 2 Lattice structure, morphology, and composition of sulfide nanosheets. (a) XRD spectra for C-nano-O and CA-nano- $x$. Lattice structure evolves from $\mathrm{Cu}_{7} \mathrm{~S}_{4}$ to $\mathrm{Ag}_{2} \mathrm{~S}$ with increased $\mathrm{Ag}$ concentration. (b) SEM image for CA-nano-4, nanosheet structure remains with shape distortion. (c) Side-view TEM of stacked CA-nano-2, morphology is also shown in Fig. S13a.† (d) SEM and EDS mapping shows uniform distribution of $\mathrm{Cu}, \mathrm{Ag}$, and $\mathrm{S}$ within the nanosheets. (e) HRTEM image of CA-nano-2 shows the lattice structure of $\mathrm{Ag}_{2} \mathrm{~S}$ viewed from direction $\left[\begin{array}{lll}1 & 0 & 0\end{array}\right]$. ( $f$ and $g$ ) HRTEM images for the basal surface. Yellow and white marks denote the defect and boundary-rich surface.

facets on the basal surface (Fig. 2f and g). The yellow line marks the boundary between two crystals that possess different structures, the white lines show the tilt of the lattice, and the yellow circles mark less-contrast areas indicating defect and amorphous regions. Combined with HRTEM images showing different lattices and the corresponding FFT patterns obtained from CA-nano-2 (Fig. S13†), one conclusion can be made is that crystal structure becomes more complicated due to the introduction of $\mathrm{Ag}$ and that the cation exchange does not have a simple outcome, a single crystal $\mathrm{Ag}_{2} \mathrm{~S}$ or dominant exposed facets, for instance.

The complicated surface outcome from cation exchange might arise from a number of factors: the hexagonal shape of $\mathrm{C}$ nano-0 triggers cation exchange from the corners and form separate grains connected by grain boundaries; the intrinsic poor crystallinity of the template leads to inconsistent reaction tendencies at different areas; the energy imposed by the low temperature $\left(50{ }^{\circ} \mathrm{C}\right)$ for cation exchange is not enough for atoms to move towards the more crystalline structure. ${ }^{40}$ Therefore, as expected, CA-nano-2 has a complicated defect and boundaryrich structure.

\section{Sulfide nanosheets for $\mathrm{CO}_{2}$ reduction}

SEM analysis shows that the nanosheets were evenly dispersed on porous carbon before $\mathrm{CO}_{2} \mathrm{R}$ (Fig. S14 $\dagger$ ). Prior in situ work with copper oxide pre-catalysts has shown that under $\mathrm{CO}_{2} \mathrm{R}$ conditions, reduction of oxides to metallic $\mathrm{Cu}$ occurs prior to the formation of gas phase products. ${ }^{41}$ We thus expected that sulfide nanosheets could have a similar behaviour, with the initial current being due to non-faradaic processes as the catalyst is reduced. Therefore, pre-reduction at negative potentials may increase selectivity for $\mathrm{CO}_{2}$ reduction. Additionally, the prereduction may facilitate the removal of the surface ligands -SCN, which might block or change the activity of the catalytic sites. Previous research show such anionic ligands could be removed under negative potentials and may induce reconstruction of the nano-scale catalysts, which further influence the performance. ${ }^{\mathbf{4 2 , 4 3}}$ Thus, for a consistent comparison, the electrodes were evaluated in the same potential sequence. All samples were tested for the same $1.5 \mathrm{~h}$ duration from the most positive potential $(-0.2 \mathrm{~V} v s$. RHE) to the most negative potential $(-1.6 \mathrm{~V}$ vs. RHE), as shown in Fig. 3 where two different cation-exchanged samples CA-nano-2 and CA-nano-4 are evaluated and compared with C-nano-0 control. Cyclic voltammetry (CV) measurements were conducted for the electrodes to show both $\mathrm{Ag}$ and $\mathrm{Cu}$ in the nanosheets are electrochemical active (Fig. S15 $\dagger$ ). ${ }^{17}$ It is worth mentioning that the current densities between the three samples are of similar values and trends, such that all catalysts had similar mass transfer limits for $\mathrm{CO}_{2}$ availability at a given potential (Fig. S16†). The electrochemical impedance spectra (EIS) indicate a lower ion transport resistance for cation exchanged samples (CA-nano-2 and CA-nano-4) compared with $\mathrm{Cu}$ sulfides (C-nano-0) (Fig. S17†).

Interestingly, at $-0.2 \mathrm{~V}$ vs. RHE, Fig. $3 \mathrm{a}$, all nanosheet catalysts produced formate exclusively before the production of other potential $2 \mathrm{e}^{-}$products: $\mathrm{CO}$ and by-product $\mathrm{H}_{2}$ from HER. However, we note that the faradaic efficiency at $-0.2 \mathrm{~V} v s$. RHE cannot be measured precisely since the potentiostat current at this potential, $\sim 0.01 \mathrm{~mA}$, is very small. Also, the larger current measured at the beginning of a run due to the non-faradic reduction of the catalyst surface sulfide or oxide layers, where not all the electrons were used for the formation of electrocatalytic $\mathrm{CO}_{2}$ reduction products, can lead to inaccuracy, especially for small negative potential regions, where large current fluctuations were observed as shown by the error bars (Fig. 3b). To assess whether formate was made just at the start or throughout the run, we tested CA-nano- 2 again at $-0.2 \mathrm{~V} v s$. RHE after the electrode has been tested at more negative potentials (Fig. S18 $\dagger$ ). Formate was still the only product detected, although the initial current density was smaller compared with as-synthesized material. One explanation is the initial current was from the reduction of the surface oxidation layer formed in the environment after the previous test instead of the reduction of the catalyst as for fresh electrode. ${ }^{44}$ Formate 

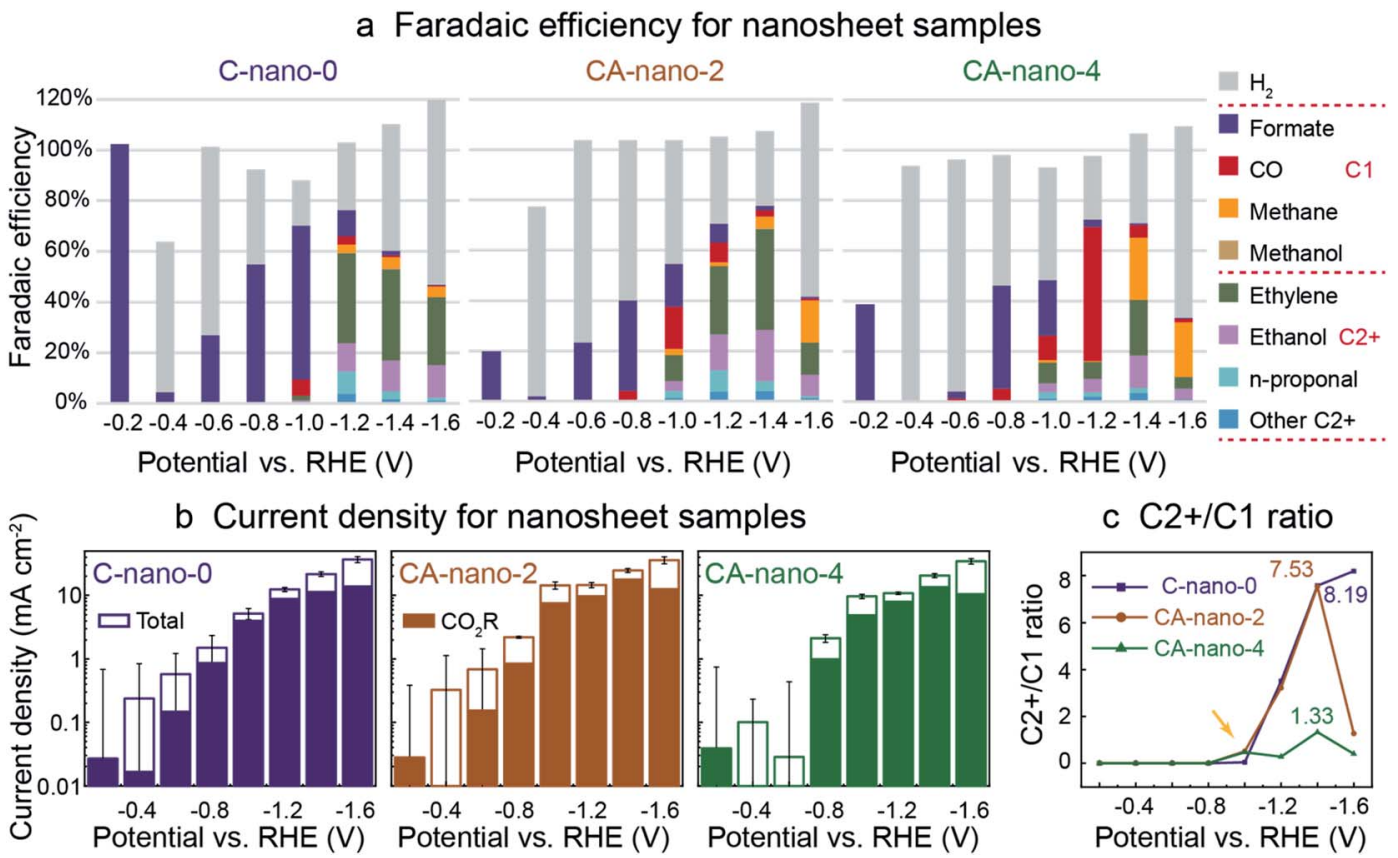

Fig. $3 \mathrm{CO}_{2}$ reduction performance for sulfide nanosheets: C-nano-0, CA-nano-2, and CA-nano-4. (a) Plot of faradaic efficiency (FE); note that all produce formate exclusively at low overpotentials $(-0.2 \mathrm{~V} v \mathrm{~s}$. RHE). (b) Total current density, solid portion of bar plot indicates partial current density for $\mathrm{CO}_{2}$ reduction products. Error bars of total current density at small negative potentials are relatively large as the current was fluctuating in time. The corresponding chronoamperometry (CA) plots are in Fig. S16. $\dagger$ (c) Plot for the ratio of $\mathrm{C} 2+$ to $\mathrm{C} 1$ products. Ag increases $\mathrm{C} 2+$ product generation at small negative potentials ( $-1.0 \mathrm{~V}$ vs. RHE). The numbers in the plot stand for the highest $\mathrm{C} 2+/ \mathrm{C} 1 \mathrm{ratio}$ obtained for each catalyst. $\mathrm{CO}_{2}$ reduction was conducted in $0.05 \mathrm{M} \mathrm{K}_{2} \mathrm{CO}_{3}$ in an experimental sequence from more positive to more negative potentials. Catalyst loading was $0.6 \mathrm{mg}$ in all cases.

was also the only product detected at $-0.1 \mathrm{~V}$ and $-0.3 \mathrm{~V} v s$. RHE for nanosheets (Fig. S19†).

For all nanosheets, $\mathrm{H}_{2}$ appears as a product at $-0.4 \mathrm{~V} v s$. RHE. At larger negative potentials its $\mathrm{FE}$ decreases and $\mathrm{FE}$ for formate increases. For C-nano-0, $\mathrm{CO}$ appears at $-1.0 \mathrm{~V} v s$. RHE $\left(\mathrm{FE}_{\mathrm{CO}}=6 \%\right) . \mathrm{C} 2+$ products, including ethylene, ethanol, and $\mathrm{C} 3$ products like $n$-propanol, appear at $-1.0 \mathrm{~V} v s$. RHE in trace amounts and dominate at $-1.2 \mathrm{~V} v s$. RHE with the ratio of $\mathrm{C} 2+$ to $\mathrm{C} 1$ products of 3.51. This ratio further increases when a more negative potential is applied, 7.57 and 8.19 for $-1.4 \mathrm{~V}$ and $-1.6 \mathrm{~V} v$ s. RHE, respectively (Fig. 3c). However, this increase comes from the decrease of formate and methane, rather than increased production in $\mathrm{C} 2+$ products, and an increase in $\mathrm{H}_{2}$ production is also clearly shown since $-1.0 \mathrm{~V} v \mathrm{v}$. RHE (Fig. S20†).

CA-nano-2 starts to produce noticeable $\mathrm{C} 2+$ products, including ethylene (10\%), ethanol (4\%), and $n$-propanol (3\%) at $-1.0 \mathrm{~V}$ vs. RHE, more positive than for C-nano-0. Also, the overall $\mathrm{CO}_{2}$ reduction products dominate at $-1.4 \mathrm{~V} v s$. RHE ( $77.7 \%$ ), which is shifted from $-1.2 \mathrm{~V}$ for C-nano-0; this may be attributed to better HER suppression at more negative potentials as a result of the $\mathrm{Ag}$ content. ${ }^{18}$ For CA-nano- 2 at $-1.4 \mathrm{~V} v$ s. RHE, the faradaic efficiency for $\mathrm{C} 2+$ products is $68.6 \%$, and the ratio of $\mathrm{C} 2+$ over $\mathrm{C} 1$ products is 7.53 . The $\mathrm{C} 2+/ \mathrm{C} 1$ ratio is similar to that of the control (Fig. 3c), but with a smaller FE for $\mathrm{H}_{2}$. The introduction of $\mathrm{Ag}$ leads to an increase in $\mathrm{CO}$ production compare to the control, with the maximum $\mathrm{FE}$ reached $-1.0 \mathrm{~V}$ vs. RHE. When a more negative potential is applied, the FE for $\mathrm{CO}$ decreases, which could be a result of $\mathrm{CO}$ diffusion to $\mathrm{Cu}$ where it is further reduced to $\mathrm{C} 2+$ products. $^{8} \mathrm{At}-1.6 \mathrm{~V} v \mathrm{~s}$. RHE, where $\mathrm{Ag}$ has less contribution to reducing $\mathrm{CO}_{2}$ to $\mathrm{CO}$ but instead increases HER, methane becomes the dominant product. ${ }^{45}$

For CA-nano-4, where $\mathrm{Ag} / \mathrm{Cu}$ ratio is $25, \mathrm{CO}$ production from $\mathrm{Ag}$ becomes the primary product, especially at $-1.2 \mathrm{~V} v$ s. RHE (53\%), much higher than that of CA-nano-2 (8\%). Also, methane is a dominant product at negative potentials $(25 \%$ at $-1.4 \mathrm{~V} v s$. RHE). One explanation for the large increase in $\mathrm{C} 1$ products might be that the increased concentration of $\mathrm{Ag}$ breaks up the continuous $\mathrm{Cu}$ surface, making the $\mathrm{CO}-\mathrm{CO}$ binding difficult. ${ }^{46}$ Thus, instead of making $\mathrm{C} 2$ products like ethylene and ethanol, conversion of the $\mathrm{CO}$ intermediate forms methane. Indeed, for this catalyst, the highest $\mathrm{C} 2+/ \mathrm{C} 1$ ratio was only 1.33 (Fig. 3c). Similar to the other nanosheet samples, with more negative potential applied, $\mathrm{H}_{2}$ became the dominant product, which also caused a decrease in the current density for overall $\mathrm{CO}_{2}$ reduction at $-1.6 \mathrm{~V} v$ s. RHE where more surface has been occupied by the $\mathrm{H}$ absorbent for $\mathrm{H}_{2}$, instead of performing $\mathrm{CO}_{2}$ reduction.

\section{Sulfides on Cu foil. (C-foil- $x$ and CA-foil- $x-y$ )}

For bimetallic sulfides on $\mathrm{Cu}$ foil, the crystal size of the $\mathrm{Cu}$ sulfide template (C-foil- $x, x$ denoting current density, Table 2) can be controlled by the current density during the electrooxidation process. Larger and more defined grains are 
produced at higher current densities (Fig. 4a). For cationexchanged samples (CA-foil- $x-y$ ), the $\mathrm{Ag} / \mathrm{Cu}$ mass ratio increases as more $\mathrm{Ag}$ precursor is added during the cation exchange (Fig. S21 $\dagger$ ). With lower Ag concentrations (CA-foil-2010), the $\mathrm{Ag}$ and $\mathrm{S}$ were uniformly distributed across the surface (Fig. 4b and c). SEM image from the side view indicates the thickness of $10 \mathrm{~s}$ of microns, consistent with the calculated modified $\mathrm{Cu}$ thickness (Fig. 4d, ESI $\dagger$ ). Also, compared with Cfoil-20, the surface of the cation-exchanged counterpart CAfoil-20-10 transformed into a rippled structure composed of finer grains, with empty spaces between layers, demonstrated by zoomed-in images, that might be beneficial for the transport of reactants and products (Fig. 4e and f). However, with further increased $\mathrm{Ag}$ precursor $\mathrm{AgNO}_{3}, \mathrm{Ag}$ nucleation on the surface through the reduction of $\mathrm{Ag}^{+}$to metallic $\mathrm{Ag}$ instead of exchanging $\mathrm{Cu}^{+}$can be observed (CA-foil-20-40). Ag concentration at the newly merged flower-like flakes is clearly shown in
Fig. $4 \mathrm{~g}$ and $\mathrm{S} 22 . \dagger$ When the particle size of $\mathrm{Cu}$ sulfides was too large (C-foil-40), the cation-exchanged counterpart CA-foil-40-40 with enough $\mathrm{Ag}$ precursor $(40 \mathrm{mg}$ ) grow into a triangle structure (Fig. S23†).

\section{Evolution of sulfide catalysts during the $\mathrm{CO}_{2}$ reduction}

Bimetallic sulfides on $\mathrm{Cu}$ foil (CA-foil- $x-y$ ) with a variety of $\mathrm{Ag}$ concentrations were tested in the potential range from $-0.8 \mathrm{~V}$ to $-1.4 \mathrm{~V} v s$. RHE. If considering ethylene as the target product, CA-foil-20-40 with high surface Ag concentration at $-1.2 \mathrm{~V} v s$. RHE gave the best performance $\left(\mathrm{FE}_{\text {ethylene }}=34 \%\right.$, Fig. $5 \mathrm{a}$ and $\mathrm{S} 24 \dagger)$. However, results of different runs show large variations in terms of both FE and current density, with selectivity to ethylene and liquid $\mathrm{C} 2+$ products initially improving and then declining ( 3 tests at $-1.0 \mathrm{~V} v s$. RHE and then 3 at $-1.2 \mathrm{~V} v s$. RHE, Fig. S25 $\dagger$ ). The morphology after reduction also shows obvious change from the fresh sample, which may come from the

\section{a Cu sulfides with different current density of electro-oxidation}

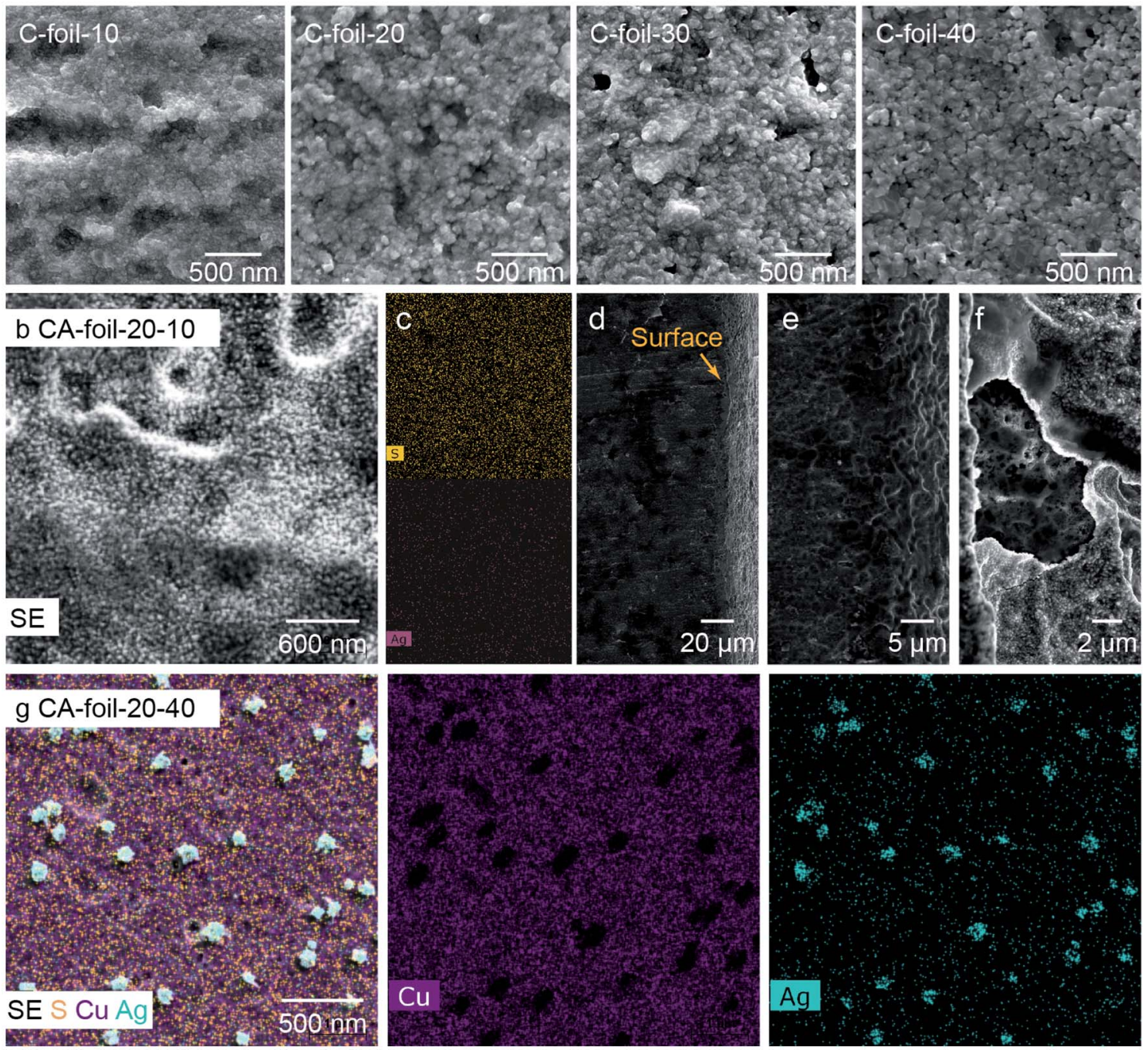

Fig. 4 Morphology characterization for sulfides on Cu foil. (a) SEM images for Cu sulfides (C-foil- $x$ ) obtained from the sulfurization of $\mathrm{Cu}(\mathrm{OH})_{2}$ achieved by electro-oxidation at the current density of 10,20,30, and $40 \mathrm{~mA} \mathrm{~cm}{ }^{-2}$. Morphology (b) and elemental distribution (c) from top view and side view ( $d-f)$ of bimetallic sulfides on Cu foil (CA-foil- $x-y)$ with moderate Ag concentration and extra Ag concentration (g). 


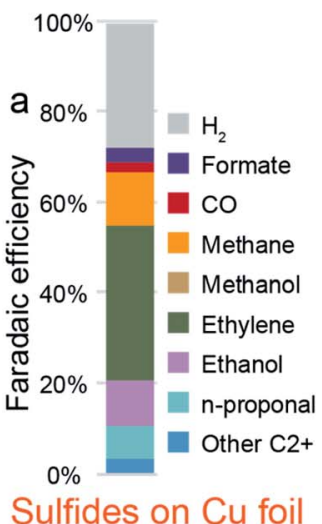

Sulfides on Cu foil
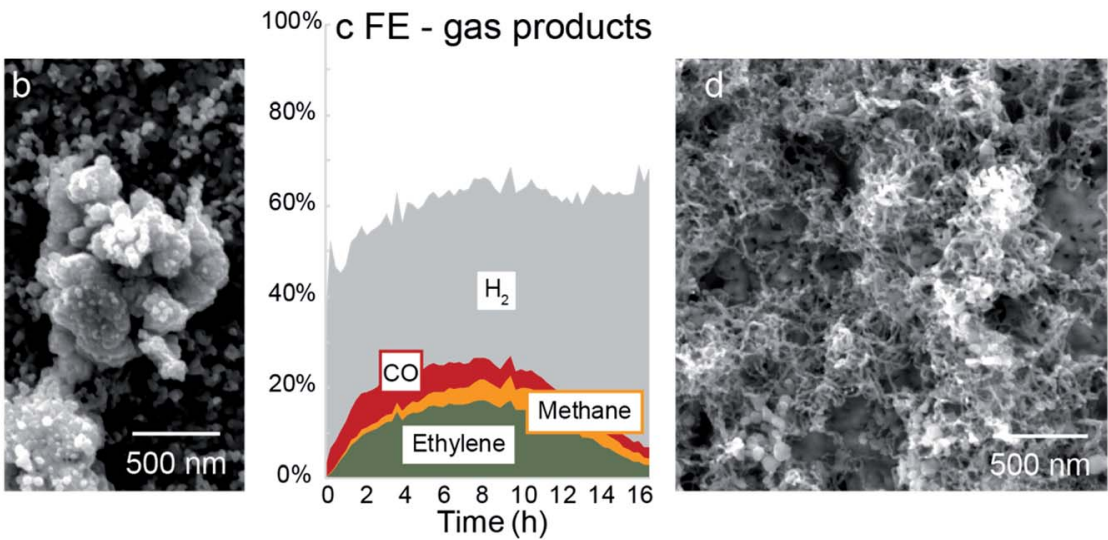

$100 \%$ f FE - gas products
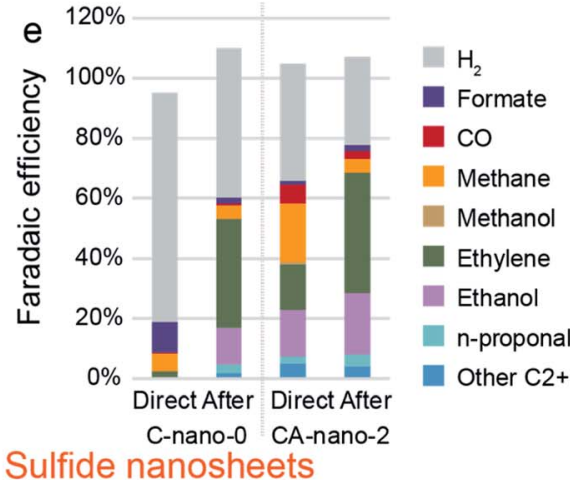

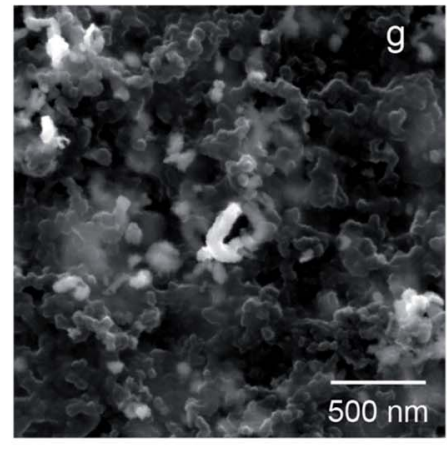

Fig. 5 Evolution of catalysts and corresponding products change during $\mathrm{CO}_{2}$ reduction. (a) Faradaic efficiency plot for CA-foil-20-40 at $-1.2 \mathrm{~V}$ vs. RHE. (b) Morphology of CA-foil-20-40 after $\mathrm{CO}_{2}$ reduction. Corresponding current plot is in Fig. S24. $\dagger$ (c) Faradaic efficiency for gas products. Sample: CA-foil-20-40. Test condition: $-1.0 \mathrm{~V}$ vs. RHE for $16 \mathrm{~h}$. Corresponding current plot is in Fig. S26. $\dagger$ (d) SEM image of CA-foil-20-40 after test. (e) Comparison of sulfide nanosheet $\mathrm{C}$-nano- 0 and CA-nano-2 between directly tested at $-1.4 \mathrm{~V} v$ s. RHE (left bar plot) and tested after prereduction at other negative potentials (right bar plot). (f) Faradaic efficiency for gas products. Sample: CA-nano-4. Test condition: $-1.4 \mathrm{~V}$ vs. RHE for $13 \mathrm{~h}$. Corresponding current plot is in Fig. S29. $\dagger$ (g) SEM image of CA-nano-4 after test.

reaction between the active surface and the reactant and intermediates (Fig. 5b).

To further investigate this performance change, assynthesized CA-foil-20-40 was directly tested at $-1.0 \mathrm{~V}$ vs. RHE for $16 \mathrm{~h}$. The current was in the range of $8-12 \mathrm{~mA} \mathrm{~cm}^{-2}$ during the test, Fig. S26. $\uparrow$ Faradaic efficiency for the gas products is plotted in Fig. 5c. $\mathrm{CO}$ was the first gas product of $\mathrm{CO}_{2}$ reduction to be observed and reaches a maximum in $\mathrm{FE}$ at 2 hours. Ethylene and methane increased with the consumption of CO, and $\mathrm{FE}$ for ethylene rose from $0 \%$ at first to $17 \%$ at $8 \mathrm{~h}$. As the plot shows, the product profile undergoes continuous change during $\mathrm{CO}_{2}$ reduction, with the optimal working region for ethylene being between 6 to $10 \mathrm{~h}$.

The evolution of the catalyst surface may explain the performance change. ${ }^{\mathbf{1 8 , 4 7}}$ Fig. $5 \mathrm{~d}$ is the SEM image of the catalyst after the $16 \mathrm{~h}$ reduction. The surface morphology changes from the particle shape into the nest structure composed of filaments with a diameter of $\sim 20 \mathrm{~nm}$, which appears to have a higher surface area compared with the fresh sample. The increased roughness of the catalyst during the $\mathrm{CO}_{2}$ reduction might be one reason for the change of gas product distribution since the nest composed of the 1D filament structure possesses both high surface area and good electrical conductivity derived from the interconnected nature and structural stability compared with nanoparticle counterparts. ${ }^{48}$

C-foil- $x$ also undergoes similar morphology change under $\mathrm{CO}_{2} \mathrm{R}$ conditions, with smaller grains (C-foil-10), the surface evolved into a nest structure composed of filaments (diameter: 40 $\mathrm{nm}$ ). The time evolution of the catalyst is also influenced by the particle size of $\mathrm{Cu}$ sulfides on $\mathrm{Cu}$ foil, as the grain size increases as a higher current applied in the electro-oxidation step, the nest structure evolved from $\mathrm{CO}_{2} \mathrm{R}$ that possess high roughness and sufficient gas pathway, which might be beneficial, gradually disappears and is replaced by large particles (Fig. S27 $\dagger$ ). According to the research on oxide-derived copper. The surface copper oxide may be reduced to metallic copper under negative potential, while other groups have reported that the residual underlying oxygen is beneficial for $\mathrm{CO}_{2}$ reduction. ${ }^{25,49}$ The sulfides on $\mathrm{Cu}$ foil may also go through a similar process as $\mathrm{Cu}$ oxides, and the sulfur will eventually be depleted such that the catalyst will be metallic copper; thus the depletion of sulfur may result in the evolution of morphology and performance. ${ }^{50}$

Besides, as previously mentioned, for sulfides on the $\mathrm{Cu}$ foil electrode, there is a limit for the introduction of $\mathrm{Ag}$ because the 
cation exchange of $\mathrm{Cu}^{+}$by $\mathrm{Ag}^{+}$competes with the direct nucleation on the electrode surface. Thus, in order to create an Agrich surface by other means, we deposited $100 \mathrm{~nm} \mathrm{Ag}$ by an Ebeam evaporator onto the $\mathrm{Cu}$ sulfides layer. However, when tested at $-1.1 \mathrm{~V} v s$. RHE, the potential most beneficial for $\mathrm{Ag}$ foil to produce $\mathrm{CO},{ }^{51}$ the morphology change from the flat overlayer to more complex nest structures during the $\mathrm{CO}_{2}$ reduction still occurred and exposed the underlying $\mathrm{Cu}$ sites. As a result, the product distribution was very different from that expected from a silver-rich surface ${ }^{52}$ (Fig. S28†).

\section{Activation of cation-exchanged nanosheets}

For CA-nano- $x$ nanosheets, when put directly under $\mathrm{CO}_{2}$ reduction conditions, the performance is far from ideal. Thus we tried to employ pre-reduction under other negative potentials as an activation method to improve $\mathrm{CO}_{2} \mathrm{R}$ selectivity. As shown in Fig. 5e, freshly prepared C-nano-0 and CA-nano-2 were directly placed at $-1.4 \mathrm{~V} v s$. RHE, and the results are compared with that after pre-reduction at other negative potentials. For direct, much more $\mathrm{H}_{2}$ was produced compared with the prereduced electrode results, the $\mathrm{FE}$ for $\mathrm{H}_{2}$ was $76 \%$ for C-nano0 and $39 \%$ for CA-nano-2, while for pre-reduced samples, the number was only $50 \%$ and $30 \%$, respectively. The product distribution of $\mathrm{CO}_{2}$ reduction also varies from the pre-reduced electrodes. For example, for fresh C-nano-0, the major $\mathrm{CO}_{2}$ reduction products are $\mathrm{C} 1$ species, including formate $(10 \%)$ and methane $(6 \%)$. In contrast, when the sample was tested at the same potential after pre-reduction, there were mainly $\mathrm{C} 2+$ products. The situation was similar for cation exchanged nanosheets. The total FE for $\mathrm{C} 2+$ products for fresh CA-nano-2 was $38.02 \%$, only half the $\mathrm{C} 2+$ products observed for the prereduced electrode $(69 \%)$.

After $\mathrm{CO}_{2}$ reduction, as expected, the adjacent nanosheets were evolved into a filament structure with a diameter of $\sim 100 \mathrm{~nm}$, similar to the diameter of the synthesized nanosheets, and the product profile changes accordingly (Fig. $5 \mathrm{f}$ and $\mathrm{g})$. The change might be related to the surface ligands, which may affect electrochemical behavior and the stability of nanomaterials, yet more characterizations need to be done to confirm this. ${ }^{\mathbf{4 2 , 5 3 , 5 4}}$ Additionally, for C-nano-0, the $\mathrm{Cu}$ was transformed into large clusters $(\sim 500 \mathrm{~nm}$, Fig. S30†), different from the filament structure of CA-nano-2. This might come from the difference in the $\mathrm{CO} / \mathrm{CO}_{2}$ binding energy on $\mathrm{Cu}$ and Ag. ${ }^{55}$ With higher binding energy between the $\mathrm{Cu}$ and $\mathrm{CO} / \mathrm{CO}_{2}$ facilitate the mobility of the anchored $\mathrm{Cu}$, thus resulting in the aggregation. However, the $\mathrm{Ag}$ added tothe CA-nano-2 has smaller binding energy with $\mathrm{CO} / \mathrm{CO}_{2}$ and confined the mobility, and the spatial separation of the nanosheets prevents further agglomeration.

\section{Conclusions}

We have demonstrated that $\mathrm{Cu}$ sulfides can be used as a template for cation exchange to achieve bimetallic $\mathrm{Ag} / \mathrm{Cu}$ sulfide catalysts with a well-controlled $\mathrm{Ag} / \mathrm{Cu}$ mass ratio by changing the concentration of $\mathrm{Ag}$ precursor $\mathrm{AgNO}_{3}$. For nanosheets, the $\mathrm{Ag} / \mathrm{Cu}$ ratio can reach 25 with the nanosheet structure remaining, while it is difficult to produce an Ag-rich surface beginning with sulfides on $\mathrm{Cu}$ foil. Formate was the only product detected at low overpotentials $(-0.2 \mathrm{~V}$ vs. RHE), and with the introduction of moderate $\mathrm{Ag}$, nanosheet catalysts showed increased $\mathrm{C} 2+$ product generation for $\mathrm{CO}_{2}$ reduction. The product profiles appear to be influenced by $\mathrm{CO}$ availability controlled by Ag concentration, suggesting a possible tandem catalytic mechanism. The reconstruction of the catalyst during $\mathrm{CO}_{2}$ reduction increased the production of multi-carbon products.

The cation exchange method can be further applied to other bimetallic or trimetallic chalcogenides like phase segregated $\mathrm{Cu}-\mathrm{Au}$ sulfides, ${ }^{40} \mathrm{Cu}-\mathrm{Ni}$ selenides, ${ }^{56} \mathrm{Cu}-\mathrm{Co}$ sulfides nanoboxes, ${ }^{57}$ and $\mathrm{CuInS}_{2}$-doped $\mathrm{ZnS},{ }^{58}$ and could potentially be used for multifunctional photo/electrocatalysis. With modifications of ligands or additives during the cation exchange method, may realize the control of even $v s$. uneven distribution of two elements with the same overall concentration that can be employed as a great test field for mechanism investigation.

\section{Author contributions}

Jinghan Li and J. W. A. conceptualized the study, and JWA acquired funding for it. Jinghan Li and Junrui Li developed synthesis methodology and analytical chemistry methods. Jinghan Li performed all synthesis and conducted the electrochemical experiments, XRD, XPS, ICP, AFM, and SEM characterization and data interpretation. Chaochao Dun performed TEM characterization using funding acquired by Jeffrey J. Urban. Wenshu Chen performed synthesis. Di Zhang and Jiajun Gu provided advice on data analysis and mentorship. Jinghan Li and JWA wrote the original draft of the manuscript and all authors contributed to its final editing.

\section{Conflicts of interest}

There are no conflicts to declare.

\section{Acknowledgements}

This material is based on the work supported by the Joint Center for Artificial Photosynthesis (JCAP), a DOE Energy Innovation Hub, supported through the Office of Science of the U.S. Department of Energy under Award Number DESC0004993. Transmission electron microscopy was performed at the Molecular Foundry, which was supported by the Office of Science, Office of Basic Energy Sciences of the U.S. Department of Energy under contract no. DE-AC02-05CH11231. J. L. acknowledges financial support from the China Scholarship Council and experimental help and support from group members during this challenging time.

\section{References}

1 O. S. S. Bushuyev, P. De Luna, C. T. T. Dinh, L. Tao, G. Saur, J. van de Lagemaat, S. O. O. Kelley and E. H. H. Sargent, What 
Should We Make with $\mathrm{CO}_{2}$ and How Can We Make It?, Joule, 2018, 2, 825-832.

2 M. Jouny, W. Luc and F. Jiao, General Techno-Economic Analysis of $\mathrm{CO}_{2}$ Electrolysis Systems, Ind. Eng. Chem. Res., 2018, 57, 2165-2177.

3 S. Nitopi, E. Bertheussen, S. B. Scott, X. Liu, A. K. Engstfeld, S. Horch, B. Seger, I. E. L. L. Stephens, K. Chan, C. Hahn, J. K. Nørskov, T. F. Jaramillo and I. Chorkendorff, Progress and Perspectives of Electrochemical $\mathrm{CO}_{2}$ Reduction on Copper in Aqueous Electrolyte, Chem. Rev., 2019, 119, 7610-7672.

4 S. Popović, M. Smiljanić, P. Jovanovič, J. Vavra, R. Buonsanti and N. Hodnik, Stability and Degradation Mechanisms of Copper-Based Catalysts for Electrochemical $\mathrm{CO}_{2}$ Reduction, Angew. Chem., Int. Ed., 2020, 59, 14736-14746.

5 Y. Hori Electrochemical $\mathrm{CO}_{2}$ Reduction on Metal Electrodes, in Modern Aspects of Electrochemistry, ed. C. G. Vayenas, R. E. White and M. E. Gamboa-Aldeco, Springer, New York, NY, 2008, vol. 29, pp. 89-189.

6 K. P. Kuhl, E. R. Cave, D. N. Abram and T. F. Jaramillo, New Insights into the Electrochemical Reduction of Carbon Dioxide on Metallic Copper Surfaces, Energy Environ. Sci., 2012, 5, 7050.

7 G. Gurudayal, D. Perone, S. Malani, Y. Lum, S. Haussener and J. W. Ager, Sequential Cascade Electrocatalytic Conversion of Carbon Dioxide to C-C Coupled Products, ACS Appl. Energy Mater., 2019, 2, 4551-4559.

8 Y. Lum and J. W. Ager, Sequential Catalysis Controls Selectivity in Electrochemical $\mathrm{CO}_{2}$ Reduction on $\mathrm{Cu}$, Energy Environ. Sci., 2018, 11, 2935-2944.

9 D. Ren, B. S. H. Ang and B. S. Yeo, Tuning the Selectivity of Carbon Dioxide Electroreduction toward Ethanol on OxideDerived $\mathrm{Cu}_{\mathrm{x}} \mathrm{Zn}$ Catalysts, ACS Catal., 2016, 6, 8239-8247.

10 C. Chen, Y. Li, S. Yu, S. Louisia, J. Jin, M. Li, M. B. Ross and P. Yang, Cu-Ag Tandem Catalysts for High-Rate $\mathrm{CO}_{2}$ Electrolysis toward Multicarbons, Joule, 2020, 4, 1688-1699.

11 J. Huang, M. Mensi, E. Oveisi, V. Mantella and R. Buonsanti, Structural Sensitivities in Bimetallic Catalysts for Electrochemical $\mathrm{CO}_{2}$ Reduction Revealed by $\mathrm{Ag}-\mathrm{Cu}$ Nanodimers, J. Am. Chem. Soc., 2019, 141, 2490-2499.

12 S. Lee, G. Park and J. Lee, Importance of Ag-Cu Biphasic Boundaries for Selective Electrochemical Reduction of $\mathrm{CO}_{2}$ to Ethanol, ACS Catal., 2017, 7, 8594-8604.

13 C. G. Morales-Guio, E. R. Cave, S. A. Nitopi, J. T. Feaster, L. Wang, K. P. Kuhl, A. Jackson, N. C. Johnson, D. N. Abram, T. Hatsukade, C. Hahn and T. F. Jaramillo, Improved $\mathrm{CO}_{2}$ Reduction Activity towards $\mathrm{C} 2+$ Alcohols on a Tandem Gold on Copper Electrocatalyst, Nat. Catal., 2018, 1, 764-771.

14 L. R. L. Ting, O. Piqué, S. Y. Lim, M. Tanhaei, F. Calle-Vallejo and B. S. Yeo, Enhancing $\mathrm{CO}_{2}$ Electroreduction to Ethanol on Copper-Silver Composites by Opening an Alternative Catalytic Pathway, ACS Catal., 2020, 10, 4059-4069.

15 D. Ren, J. Gao, L. Pan, Z. Wang, J. Luo, S. M. Zakeeruddin, A. Hagfeldt and M. Grätzel, Atomic Layer Deposition of $\mathrm{ZnO}$ on $\mathrm{CuO}$ Enables Selective and Efficient
Electroreduction of Carbon Dioxide to Liquid Fuels, Angew. Chem., 2019, 131, 15178-15182.

16 D. Kim, C. Xie, N. Becknell, Y. Yu, M. Karamad, K. Chan, E. J. Crumlin, J. K. Nørskov and P. Yang, Electrochemical Activation of $\mathrm{CO}_{2}$ through Atomic Ordering Transformations of AuCu Nanoparticles, J. Am. Chem. Soc., 2017, 139, 8329-8336.

17 X. Lv, L. Shang, S. Zhou, S. Li, Y. Wang, Z. Wang, T. Sham, C. Peng and G. Zheng, Electron-Deficient $\mathrm{Cu}$ Sites on $\mathrm{Cu}_{3} \mathrm{Ag}_{1}$ Catalyst Promoting $\mathrm{CO}_{2}$ Electroreduction to Alcohols, Adv. Energy Mater., 2020, 10, 2001987.

18 L. Wang, D. C. Higgins, Y. Ji, C. G. Morales-Guio, K. Chan, C. Hahn and T. F. Jaramillo, Selective Reduction of CO to Acetaldehyde with CuAg Electrocatalysts, Proc. Natl. Acad. Sci. U. S. A., 2020, 117, 12572-12575.

19 D. Kim, J. Resasco, Y. Yu, A. M. Asiri and P. Yang, Synergistic Geometric and Electronic Effects for Electrochemical Reduction of Carbon Dioxide Using Gold-Copper Bimetallic Nanoparticles, Nat. Commun., 2014, 5, 1-8.

20 Y. C. Li, Z. Wang, T. Yuan, D.-H. Nam, M. Luo, J. Wicks, B. Chen, J. Li, F. Li, F. P. G. de Arquer, Y. Wang, C.-T. Dinh, O. Voznyy, D. Sinton, E. H. Sargent, F. P. Garcia de Arquer, Y. Wang, C.-T. Dinh, O. Voznyy, D. Sinton and E. H. Sargent, Binding Site Diversity Promotes $\mathrm{CO}_{2}$ Electroreduction to Ethanol, J. Am. Chem. Soc., 2019, 141, 8584-8591.

21 E. L. Clark, C. Hahn, T. F. Jaramillo and A. T. Bell, Electrochemical $\mathrm{CO}_{2}$ Reduction over Compressively Strained CuAg Surface Alloys with Enhanced Multi-Carbon Oxygenate Selectivity, J. Am. Chem. Soc., 2017, 139, 1584815857.

22 N. Martić, C. Reller, C. Macauley, M. Löffler, A. M. Reichert, T. Reichbauer, K.-M. Vetter, B. Schmid, D. McLaughlin, P. Leidinger, D. Reinisch, C. Vogl, K. J. J. Mayrhofer, I. Katsounaros and G. Schmid, $\mathrm{Ag}_{2} \mathrm{Cu}_{2} \mathrm{O}_{3}-$ a Catalyst Template Material for Selective Electroreduction of $\mathrm{CO}$ to $\mathrm{C}_{2+}$ Products, Energy Environ. Sci., 2020, 13, 2993-3006.

23 T. Ling, M. Jaroniec and S. Qiao, Recent Progress in Engineering the Atomic and Electronic Structure of Electrocatalysts via Cation Exchange Reactions, $A d v$. Mater., 2020, 32, 2001866.

24 L. Wang, S. Nitopi, A. B. Wong, J. L. Snider, A. C. Nielander, C. G. Morales-Guio, M. Orazov, D. C. Higgins, C. Hahn and T. F. Jaramillo, Electrochemically Converting Carbon Monoxide to Liquid Fuels by Directing Selectivity with Electrode Surface Area, Nat. Catal., 2019, 1-7.

25 Y. Lum and J. W. Ager, Stability of Residual Oxides in OxideDerived Copper Catalysts for Electrochemical $\mathrm{CO}_{2}$ Reduction Investigated with ${ }^{18} \mathrm{O}$ Labeling, Angew. Chem., Int. Ed., 2018, 57, 551-554.

26 Y. Lum and J. W. Ager, Evidence for Product-Specific Active Sites on Oxide-Derived $\mathrm{Cu}$ Catalysts for Electrochemical $\mathrm{CO}_{2}$ Reduction, Nat. Catal., 2019, 2, 86-93.

27 Y. Huang, Y. Chen, T. Cheng, L.-W. W. Wang and W. A. Goddard, Identification of the Selective Sites for Electrochemical Reduction of $\mathrm{CO}$ to $\mathrm{C}_{2+}$ Products on Copper Nanoparticles by Combining Reactive Force Fields, 
Density Functional Theory, and Machine Learning, ACS Energy Lett., 2018, 3, 2983-2988.

28 W. T. Osowiecki, J. J. Nussbaum, G. A. Kamat, G. Katsoukis, M. Ledendecker, H. Frei, A. T. Bell and A. P. Alivisatos, Factors and Dynamics of $\mathrm{Cu}$ Nanocrystal Reconstruction under $\mathrm{CO}_{2}$ Reduction, ACS Appl. Energy Mater., 2019, 2, 7744-7749.

29 T. Kim, J. Park, Y. Hong, A. Oh, H. Baik and K. Lee, Janus to Core-Shell to Janus: Facile Cation Movement in $\mathrm{Cu}_{2-x} \mathrm{~S} / \mathrm{Ag}_{2} \mathrm{~S}$ Hexagonal Nanoplates Induced by Surface Strain Control, ACS Nano, 2019, 13, 11834-11842.

30 J. Park, J. Park, J. Lee, A. Oh, H. Baik and K. Lee, Janus Nanoparticle Structural Motif Control via Asymmetric

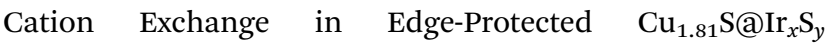
Hexagonal Nanoplates, ACS Nano, 2018, 12, 7996-8005.

31 S. Deng, Y. Shen, D. Xie, Y. Lu, X. Yu, L. Yang, X. Wang, X. Xia and J. Tu, Directional Construction of $\mathrm{Cu}_{2} \mathrm{~S}$ Branch Arrays for Advanced Oxygen Evolution Reaction, J. Energy Chem., 2019, 39, 61-67.

32 P. Lobaccaro, M. R. Singh, E. L. Clark, Y. Kwon, A. T. Bell and J. W. Ager, Effects of Temperature and Gas-Liquid Mass Transfer on the Operation of Small Electrochemical Cells for the Quantitative Evaluation of $\mathrm{CO}_{2}$ Reduction Electrocatalysts, Phys. Chem. Chem. Phys., 2016, 18, 2677726785.

33 Y. Lum, T. Cheng, W. A. Goddard and J. W. Ager, Electrochemical CO Reduction Builds Solvent Water into Oxygenate Products, J. Am. Chem. Soc., 2018, 140, 9337-9340.

34 C. Zhang, C. Yan, Z. Xue, W. Yu, Y. Xie and T. Wang, ShapeControlled Synthesis of High-Quality $\mathrm{Cu}_{7} \mathrm{~S}_{4}$ Nanocrystals for Efficient Light-Induced Water Evaporation, Small, 2016, 12, 5320-5328.

35 X. Li, Z. Yao, J. Wang, D. Li, K. Yu and Z. Jiang, A Novel Flakelike $\mathrm{Cu}_{7} \mathrm{~S}_{4}$ Solar Absorber for High-Performance Large-Scale Water Evaporation, ACS Appl. Energy Mater., 2019, 2, 51545161.

36 M. Sun, Z. Li, Q. Fang, S. Han, C. Cai, H. Li, W. Shen, X. Liu and Y. Fu, Room-Temperature Synthesized Porous $\mathrm{Cu}(\mathrm{OH})_{2} /$ $\mathrm{Cu}_{7} \mathrm{~S}_{4}$ Hybrid Nanowires as a High-Performance Electrode Material for Asymmetric Supercapacitors, J. Mater. Chem. A, 2020, 8, 724-734.

37 N. Wijeyasinghe, A. Regoutz, F. Eisner, T. Du, L. Tsetseris, Y.-H. Lin, H. Faber, P. Pattanasattayavong, J. Li, F. Yan, M. A. McLachlan, D. J. Payne, M. Heeney and T. D. Anthopoulos, Copper(I) Thiocyanate (CuSCN) HoleTransport Layers Processed from Aqueous Precursor Solutions and Their Application in Thin-Film Transistors and Highly Efficient Organic and Organometal Halide Perovskite Solar Cells, Adv. Funct. Mater., 2017, 27, 1701818.

38 Z. Yin, C. Yu, Z. Zhao, X. Guo, M. Shen, N. Li, M. Muzzio, J. Li, H. Liu, H. Lin, J. Yin, G. Lu, D. Su and S. Sun, $\mathrm{Cu}_{3} \mathrm{~N}$ Nanocubes for Selective Electrochemical Reduction of $\mathrm{CO}_{2}$ to Ethylene, Nano Lett., 2019, 19, 8658-8663.

39 J. Xu, J. Cui, C. Guo, Z. Zhao, R. Jiang, S. Xu, Z. Zhuang, Y. Huang, L. Wang and Y. Li, Ultrasmall $\mathrm{Cu}_{7} \mathrm{~S}_{4} @ \mathrm{MoS}_{2}$ Hetero-Nanoframes with Abundant Active Edge Sites for
Ultrahigh-Performance Hydrogen Evolution, Angew. Chem., Int. Ed., 2016, 55, 6502-6505.

40 Y. Zhao, H. Wang, W. Zhao, X. Zhao, J.-J. Xu and H.-Y. Chen, Dark-Field Imaging of Cation Exchange Synthesis of $\mathrm{Cu}_{2-\mathrm{x}} \mathrm{S} @ \mathrm{Au}_{2} \mathrm{~S} @ \mathrm{Au}$ Nanoplates toward the Plasmonic Enhanced Hydrogen Evolution Reaction, ACS Appl. Mater. Interfaces, 2021, 13, 6515-6521.

41 L. Mandal, K. R. Yang, M. R. Motapothula, D. Ren, P. Lobaccaro, A. Patra, M. Sherburne, V. S. Batista, B. S. Yeo, J. W. Ager, J. Martin and T. Venkatesan, Investigating the Role of Copper Oxide in Electrochemical $\mathrm{CO}_{2}$ Reduction in Real Time, ACS Appl. Mater. Interfaces, 2018, 10, 8574-8584.

42 D. Kim, S. Yu, F. Zheng, I. Roh, Y. Li, S. Louisia, Z. Qi, G. A. Somorjai, H. Frei, L.-W. Wang and P. Yang, Selective $\mathrm{CO}_{2}$ Electrocatalysis at the Pseudocapacitive Nanoparticle/ Ordered-Ligand Interlayer, Nat. Energy, 2020, 5, 1032-1042.

43 D. Kim, C. S. Kley, Y. Li and P. Yang, Copper Nanoparticle Ensembles for Selective Electroreduction of $\mathrm{CO}_{2}$ to $\mathrm{C}_{2}-\mathrm{C}_{3}$ Products, Proc. Natl. Acad. Sci. U. S. A., 2017, 114, 1056010565.

44 Y. Li, D. Kim, S. Louisia, C. Xie, Q. Kong, S. Yu, T. Lin, S. Aloni, S. C. Fakra and P. Yang, Electrochemically Scrambled Nanocrystals Are Catalytically Active for $\mathrm{CO}_{2}$-toMulticarbons, Proc. Natl. Acad. Sci. U. S. A., 2020, 117, 9194-9201.

45 X. Wang, A. Xu, F. Li, S. F. Hung, D. H. Nam, C. M. Gabardo, Z. Wang, Y. Xu, A. Ozden, A. S. Rasouli, A. H. Ip, D. Sinton and E. H. Sargent, Efficient Methane Electrosynthesis Enabled by Tuning Local $\mathrm{CO}_{2}$ Availability, J. Am. Chem. Soc., 2020, 142, 3525-3531.

46 S. Ma, M. Sadakiyo, M. Heim, R. Luo, R. T. Haasch, J. I. Gold, M. Yamauchi and P. J. A. Kenis, Electroreduction of Carbon Dioxide to Hydrocarbons Using Bimetallic Cu-Pd Catalysts with Different Mixing Patterns, J. Am. Chem. Soc., 2017, 139, 47-50.

47 Y. Lum, B. Yue, P. Lobaccaro, A. T. Bell and J. W. Ager, Optimizing C-C Coupling on Oxide-Derived Copper Catalysts for Electrochemical $\mathrm{CO}_{2}$ Reduction, J. Phys. Chem. C, 2017, 121, 14191-14203.

48 M. M. Flores Espinosa, T. Cheng, M. Xu, L. Abatemarco, C. Choi, X. Pan, W. A. Goddard, Z. Zhao and Y. Huang, Compressed Intermetallic $\mathrm{PdCu}$ for Enhanced Electrocatalysis, ACS Energy Lett., 2020, 3672-3680.

49 M. Favaro, H. Xiao, T. Cheng, W. A. Goddard and E. J. Crumlin, Subsurface Oxide Plays a Critical Role in $\mathrm{CO}_{2}$ Activation by $\mathrm{Cu}(111)$ Surfaces to Form Chemisorbed $\mathrm{CO}_{2}$, the First Step in Reduction of $\mathrm{CO}_{2}$, Proc. Natl. Acad. Sci. U. S. A., 2017, 114, 6706-6711.

50 M. B. McNeil and B. J. Little, Corrosion Mechanisms for Copper and Silver Objects in Near-Surface Environments, $J$. Am. Inst. Conserv., 1992, 31, 355-366.

51 C. Kim, H. S. Jeon, T. Eom, M. S. Jee, H. Kim, C. M. Friend, B. K. Min and Y. J. Hwang, Achieving Selective and Efficient Electrocatalytic Activity for $\mathrm{CO}_{2}$ Reduction Using Immobilized Silver Nanoparticles, J. Am. Chem. Soc., 2015, 137, 13844-13850. 
52 A. S. Varela, C. Schlaup, Z. P. Jovanov, P. Malacrida, S. Horch, I. E. L. Stephens and I. Chorkendorff, $\mathrm{CO}_{2}$ Electroreduction on Well-Defined Bimetallic Surfaces: $\mathrm{Cu}$ Overlayers on Pt(111) and Pt(211), J. Phys. Chem. C, 2013, 117, 2050020508.

53 G. Collins, F. Davitt, C. O'Dwyer and J. D. Holmes, Comparing Thermal and Chemical Removal of Nanoparticle Stabilizing Ligands: Effect on Catalytic Activity and Stability, ACS Appl. Nano Mater., 2018, 1, 71297138.

54 M. Gao, Y. Zhu, Y. Liu, K. Wu, H. Lu, S. Tang, C. Liu, H. Yue, B. Liang and J. Yan, The Role of Adsorbed Oleylamine on Gold Catalysts during Synthesis for Highly Selective Electrocatalytic Reduction of $\mathrm{CO}_{2}$ to $\mathrm{CO}$, Chem. Commun., 2020, 56, 7021-7024.

55 Y. Ye, J. Qian, H. Yang, H. Su, K. J. Lee, A. Etxebarria, T. Cheng, H. Xiao, J. Yano, W. A. Goddard and E. J. Crumlin, Synergy between a Silver-Copper Surface Alloy Composition and Carbon Dioxide Adsorption and
Activation, ACS Appl. Mater. Interfaces, 2020, 12, 2537425382.

56 S. Kim, H. Mizuno, M. Saruyama, M. Sakamoto, M. Haruta, H. Kurata, T. Yamada, K. Domen and T. Teranishi, Phase Segregated $\mathrm{Cu}_{2-x} \mathrm{Se} / \mathrm{Ni}_{3} \mathrm{Se}_{4} \quad$ Bimetallic Selenide Nanocrystals Formed through the Cation Exchange Reaction for Active Water Oxidation Precatalysts, Chem. Sci., 2020, 11, 1523-1530.

57 Y. Fang, D. Luan, Y. Chen, S. Gao and X. W. (David) Lou, Synthesis of Copper-Substituted $\mathrm{CoS}_{2} @ \mathrm{Cu}_{\mathrm{x}} \mathrm{S}$ Double-Shelled Nanoboxes by Sequential Ion Exchange for Efficient Sodium Storage, Angew. Chem., 2020, 132, 26662670 .

58 A. T. Nguyen, F. Gao, D. Baucom and C. D. Heyes, CuInS $2_{2}^{-}$ Doped ZnS Quantum Dots Obtained via Non-Injection Cation Exchange Show Reduced but Heterogeneous Blinking and Provide Insights into Their Structure-Optical Property Relationships, J. Phys. Chem. C, 2020, 124, 1074410754. 